\title{
Between Scylla and Charybdis: losing balance in an age of extremes
}

\author{
Abstract \\ This article charts a course from the literature of the classical world through to some classics \\ in sociology and some more recent psychoanalytically informed work to offer a metaphor for \\ the vicissitudes of structure and fluidity in this time of turbulence and extremes. The episode \\ from Homer's Odyssey featuring the passage of Odysseus and his men between the twin \\ monsters of Scylla and Charybdis is seen as offering an image of the two tendencies of our \\ time towards extreme forms of fluidity in the form of liberalisation of markets and \\ marketization of most sectors alongside a proliferation and mutation of bureaucratic practices \\ seen as an aspect of structural conditions. The dysfunctional relation and polarisation of \\ these tendencies and their consequences are analysed in turn as leading first to a culture of \\ narcissism (Lasch, 1978), then in terms of perversion (Long 2008 and Hoggett 2010) at a \\ social as well as a socially constructed individual level. The article makes use of free \\ association and amplification in working with images and metaphors.
}

Keywords: metaphor; structure; fluidity; narcissism; perversion; cunning 


\section{Introduction}

We live in turbulent, confused and confusing times. Depending on one's location and context one's experience may go from one extreme to another in terms of how much and what kind of control and bureaucracy one might be subjected to or how much speed and enterprise be expected and demanded of one. In commercial and private business practices the tendency is towards flat structures (see GOOGLE for instance), less faith in a Panopticon (Foucalt, 1977) style of command and control or at least the emergence of doubt in their suitability, while in the arrangements of public institutions bureaucratic, procedural top down practices seem to be proliferating at least in UK and other European contexts. These extremes are what the title alludes to, but also cognisant of Hobsbawm's (1994) historical work. Yet these extremes do not exist in isolation from each other, it is the nature of their relation and how they manifest in different guises and combinations in public service institutions and what they produce that is the subject of this article.

A simple way of characterising this is given by the example of UK Home Office practices that surfaced recently in what has become known as the Windrush scandal, whereby the purposeful creation of a hostile bureaucratic environment meant the deportation and stripping of right to work, pensions and healthcare for people who were originally invited from the Caribbean British colonies to work in the UK. They were already British citizens at the time, yet many do not now have the right documents to prove such despite a lifetime in the UK. Bureaucratic target driven measures of immigration control were and are being followed to the letter, without hesitation or deviation, to curb immigrant flows, totally ignoring the historical nature of the situation or its ethical social justice dimensions.

The main argument put forward in this paper is that underlying these dynamics there is a reactive and perverse relationship between what Bauman (2000) termed the liquidity of late 
modernity and top down procedural bureaucratic measures in most public service institutions. Perversely and paradoxically, while there is a relation between them, this does not offer containment, rather it is dysfunctional, polarised, often based on reactive and reactionary notions, founded on projections and leading to an increasing disconnection between tasks and processes and a fragmented and persecutory environment.

The purpose of the paper is to track this dysfunctional dynamic between two tendencies, loosely characterised in terms of structure and fluidity, at the hand of images and classic texts. The work can be seen as strongly associational and it is heavily influenced methodologically by: a) psychoanalytic work based on free associations and amplification most often used to work with image based content, and b) Bergson and Deleuze's philosophical orientation (see also Manley, 2018). What these frameworks indicate is that an important step towards understanding may be given by discerning and acknowledging some ubiquitous processes and tendencies in social dynamics, also subject to different types of inter-relatedness. What a Deleuzian perspective offers is also a way of thinking that follows the 'becomings' of such tendencies, in other words their transformations and torsions in specific settings, which in my view is best achieved through free association and amplification processes. Thus it identifies basic differences in kind, in this case structure and fluidity as elements of analysis, while acknowledging that in reality 'things... are always mixtures' and 'only tendencies are simple and pure' (Deleuze, 1999a: 45, his italics). The mixtures vary, but one can identify these tendencies in different guises as torsions of the same, topological transformations (Massumi, 2002:ch.8), rather than totally different in kind, while at the same time some disguises are such that one pretends to be the other, as in the way quality of experience is supposed to be measurable by tick box menus of choices. The tendencies are mostly seen in terms of structure and fluidity, but also following a Bergsonian model, in their association to different manifestations, such as quality and 
quantity, also subject to a particular kind of dysfunctional relatedness in contemporary social and political dynamics. In keeping with its associational methodology the article assumes that images encapsulate complex messages, attempting therefore, at least partially, to unpack them, while allowing the images to stand as metaphors for the dynamics illustrated. It does this by drawing on some classic images: starting with the episode from Homer's Odyssey of Odysseus navigating between Scylla and Charybdis, the twin monsters standing in for the dangerous aspects of extreme fluidity and petrified structures; moving then to Bauman's ‘liquid modernity' and Weber's ‘iron cage of bureaucracy' from his classic work on The Protestant Ethic and the Spirit of Capitalism, which are then explored and elaborated with reference to Lasch's (1978) Culture of Narcissism and other more recent psychoanalytically informed perspectives. Instrumentalisation is seen as a central feature of the neoliberal practices in the public and commercial sectors; narcissism as a consequence of instrumentalisation and fluidity, and perversion as an additional and more corrosive consequence of neoliberalism than narcissism.

The key orientation of the paper is psychosocial, drawing from key sociological literature and allying this to psychoanalytically derived concepts and methodologies. Its central tenet is that there is a growing tendency towards reactive, doer/done to (Benjamin, 2004) relation between structure and fluidity, quality and quantity, which is most often unrelated and inimical to the task of institutions or organisations. As Mark Fisher (2009) also pointed out: neoliberal capitalism ideological concern with profit has not liberated us from bureaucratic control. My point is that a quantitative focus on performance is at the expense of qualitative aspects, such as the increasing corrosion of character (Sennett, 1998) and mental health in human lived experience. Where the focus on efficiency and productivity contends with aspects of ethical significance effort is seemingly expended in trying to subdue the excess fluidity, such as staff turnover for example, by procedural and/or bureaucratic means, increased hierarchical and 
regulatory controls, rather than professional ethics. However this does not address the conditions of turbulence it is trying to manage; rather it fosters an emptying out of values, a culture of shallowness, narcissism, increased turbulence and acceleration and paradoxically a drifting apart, while coming closer of the two tendencies. While the paper draws from classics in literature and sociology, psychoanalytic concepts such as narcissism and perversion give some purchase to our understanding of the lived experience that results from these dynamics.

\section{Between Scylla and Charybdis}

The episode from Homer's Odyssey provides a metaphor for our time, in spite of its ancient provenance. Odysseus is a figure of interest in its own right. Horkheimer and Adorno in their Dialectic of Enlightenment (1947: Excursus I) present him as the cunning hero of the Odyssey, itself an epic of individualism, as opposed to the Iliad, an epic of civilisations (see also Crociani-Windland, 2011: 116-122 for more on cunning). On a reflexive note my own upbringing in Southern Europe and previous training in the Classics may have influenced my choice in terms of metaphors, yet I am not alone in seeing this epic as the origin of Enlightenment and Western culture, beyond the difference between North and South that Weber (1904-05/1992) pointed to as foundational to the emergence of capitalism.

Being between Scylla and Charybdis, managing not to fall prey to either monster has come to be part of common English language. This refers to the episode of the Odyssey (Homer, Odyssey 12. $231 \mathrm{ff}$ ), when, having left Circe, who had turned some of his men to swine and back to humans, Odysseus had to navigate what Virgil (Aeneid 3. $418 \mathrm{ff}$ trans. Day-Lewis) and other classical authors thought to be the Straits of Messina. Being in dire straits is of course another proverbial expression for being beset by danger. The narrative in brief tells us that Odysseus and his men had to pass between Scylla, a six-headed monster, and Charybdis, 
a whirlpool on the opposite shore. The one imprisoned, chewed and devoured, while the other swallowed whole. On the sorceress Circe's advice Odysseus clung to Scylla's side to avoid Charybdis, being told that thus he would forfeit six men, but save the rest. He had told the men about Charybdis, but not Scylla, lest fear impair their rowing. As they approached the strait, they could hear the roar of Charybdis and as they neared it Odysseus was enthralled by its boiling turbulence and did not see Scylla's long necks stretching to swoop his men away. Watching them being devoured, Odysseus claims 'was the most sickening sight I saw in all my voyages' (Homer Odyssey, book XII trans. Butler).

Overall, the image speaks of the turbulence created when land constricts flow as happens in the geographical feature of straits and generally when water flow is constricted as when it goes down the plug-hole; in other words when structure overly restricts flow. Without delving into the science of this in detail, it may suffice to leave this as an image for the purposes of this paper. Homer gives more geographical detail though. Scylla is in a cave in a rock so high, you cannot see its peak, shrouded in mist at all seasons. The rock cannot be climbed and the cave is so high arrows cannot reach it. How many people these days feel they cannot see where the pressure comes from or get to where the power or responsibility lies? Interestingly Scylla is described as having six heads, each with three rows of teeth, twelve misshapen feet, yet her canine yelp could be thought to be that of a pup. In other words her nature is multiple and most fearful, but sounds innocuous. Nonetheless the sorceress Circe had advised this to be the lesser evil. Her advice was instrumental and utilitarian: sacrifice six men to save yourself and the rest of the crew. The six men Scylla devoured were the strongest and most able. How many restructuring processes and redundancies have the same effect?

Charybdis is not described in the same direct way: all we are given is a description of her belching and swallowing water and that she lies between low rocks with a fig tree growing 
above. It is indeed far harder to describe and understand turbulence and fluidity, as scientists, philosophers and social scientists who have struggled to get a grip on such matters would attest. Nonetheless as stated earlier, where land constricts flow turbulence is produced. Scylla's cave and rocky cliffs stand here metaphorically for imprisonment and demise by structure and Charybdis obliteration by extreme fluidity, the turbulent whirlpool able to swallow and drown us. Bauman's (2000) idea of Liquid Modernity seems to be apt in relating to turbulence.

\section{Liquid or Fluid Modernity-All that is solid melts into the air... (Marx)}

Bauman's (2000) book which bears the title of Liquid Modernity already spoke of the turbulence of our time characterised by constant mobility and change in relationships, identities, and global economics. The reality of this is part of everyone's experience and it is part of an accelerating trajectory hard to capture in any definitive way. There are signs of what Bauman characterises as a move from "pilgrims" in search of deeper meaning to "tourists" in search of multiple but fleeting social experiences. Certainly in terms of Western values we have gone from a monotheistic outlook, one God, one truth, to a pick and mix approach to belief (Luckman, 1991), yet we also see renewed searches for meaning and identity beginning to emerge and be commented on within social science and management literature (Gabriel, 2012). In terms of modernity we have moved from organised to disorganised modernity (Lash and Urry, 1987), from hardware to software to 'everyware' or ubiquitous computing (Greenfield, 2006). Boundaries of time and space have been eroded (Giddens 1990) and most of us experience information overload. Plenty of information actually results in very little knowledge as our minds stop being able to cope with the inputs. Identity is tied to consumption and choice. Choice both defines us and torments us, it is hard to choose in the midst of so much information and so little knowledge, meaning a qualitative 
aspect, ie knowledge as understanding and critical capacity, is being replaced by a quantity of facts parading as knowledge. 'Compare' sites, Linkedin and other professional network based systems are cashing in on the need to sort out the wheat from the chaff in choosing who to associate with or buy from, yet the trustworthiness of such systems has to be constantly questioned: for example a recent item of news was that product reviews are written by paid people in the most varied locations, who may never have seen the goods they offer five star reviews for. And then there are fake news...

Anthony Bryant extends some of Bauman's ideas in an article (2007) titled Liquid Modernity, Complexity and Turbulence. He begins by linking Bauman's main argument to quotes from Marx's Communist Manifesto, he sees particularly this quote as at the core of Bauman's work: 'All fixed, fast frozen relations, with their train of ancient and venerable prejudices and opinions, are swept away, all new-formed ones become antiquated before they can ossify.' I beg to agree and differ, if that can be a defensible position. It is partly true and partly untrue, in that it reflects the speed of change and yet what may be on the increase now is a changing of the same, old wine in new bottles, as the revival of populist fear driven and fear driving narratives attests. Bryant has a positive take on the turbulence and liquidity pointing out that complexity theory offers a little solace in telling us that order tends to emerge from chaos. However little order seems to be emerging as yet and liquidity is only one side of the coin. The other is the insidious structural aspect of bureaucratic management practices and how they might shape those living with them. There is a genealogy to this. For that let's go further back to one of the founding fathers of Sociology.

\section{Weber's Iron Cage of Bureaucracy (the rocks-the cave-Scylla)}

No one knows who will live in this cage (Gehäuse) in the future, or whether at the end of this tremendous development entirely new prophets will arise, or there will be 
a great rebirth of old ideas and ideals, or, if neither, mechanized petrification, embellished with a sort of convulsive self-importance. For the "last man" (letzten Menschen) of this cultural development, it might well be truly said: "Specialist without spirit, sensualist without heart; this nullity imagines that it has attained a level of humanity (Menschentums) never before achieved" [Weber 1904-05/1992, 182: translation altered]

Weber is famous for having characterised modernity in terms of increasing bureaucratic control and instrumental rationality. Parsons' translation of the original German term Gehause as 'iron cage' of bureaucracy has entered the sociological stock of terms. This is linked by Weber to rationalising processes of modernity that create particular structures and conditions, resulting in a sense of petrification and imprisonment on one side and on the other not only a fragmentation of values, but a change in quality whereby values rather than moral, become aesthetic, leaving people empty, while thinking themselves superior, a clear feature of narcissistic personalities.

Weber's image of the iron cage has been around for a long time as a potent metaphor, particularly in organisational studies. Many have used it, though since the turn of the century there has been a sense that it needed updating. Yiannis Gabriel (2005) reconceptualised it as a glass cage, to both retain the sense of imprisonment, while also conveying the aspect of surveillance so prevalent in our time. It is also suggestive of being on show, hence as he puts it '.. a medium perfectly suited to a society of spectacle, just as steel was perfectly suited to a society of mechanism' (Gabriel 2008: 314). Clegg and Baumeler (2010: 3) give a brief overview of other reconfigurations of the cage: 'a mental cage (Courpasson 2000), perhaps even reconceived as made of velvet or rubber: velvet metaphorically promises subjects the fulfilment of dreams while rubber is capable of being 'stretched to allow adequate means for escape' (Ritzer 1996: 177). Clegg and Baumeler (ibid) add their own take of 'transparent 
liquidity'. This is based heavily on Bauman's work, but their focus differs in that it shifts from consumption back to production and what happens to people at work, rather than in shopping centres or increasingly in online shopping. The increasing casualization of work, de-regulation of markets and the need for agility and flexibility of workers, able to manage uncertainty in the face of endless re-structuring, precariousness of contracts and global conditions is indeed more likely to be captured by metaphors of transparent liquidity. Yet to quote Clegg and Baumeler (ibid: 16): 'Some central questions emerge concerning the key metaphors deployed in the field. It is evident that liquidity is not everywhere; it is equally evident that iron cages are still to be found, as are glass cages'. In other words we need to think of the two tendencies in different combinations and relationships. The fluidity in the commercial sector is driving some interesting examples of perverse mixtures, whereby regulation tries to stop particular types of fluidity, such as employees' absence, by imposing fines, while retaining the right to extreme flexibility by giving workers no security of employment, either by only offering zero hour contracts or by restructuring, thereby getting round worker's protection regulations.

The latest reaction to unethical data leaks and use has seen a more conventional government response: Facebook's Mark Zuckerberg was called to account by the US government and Cambridge Analytica's Alexander Nix by the UK government over meddling in recent voting, respectively US elections and UK Brexit referendum. The General Data Protection Regulation appears to be in this case a more conventional regulatory response aimed to curb immoral, but very lucrative and power wielding fluidity of practice. While a response to big players' malpractice, it now includes everyone in more bureaucratic practices, while those bent on bending the rules may yet find fluid 'enterprising' escapes. In other words while in this case this may be seen as a containing move to curb excess fluidity and unethical practices it is also a rigid, regulatory procedural approach, which may hamper some perfectly harmless 
data sharing, while encouraging those with enough resources to find cunning ways to get out of its grasp. 'Power is measured by the speed with which responsibilities can be escaped' (Bauman and Tester 2001: 95, also cited in Clegg and Baumeler, 2010: 4). Or as the Italian saying roughly translated goes: when a law is made, a loophole can be found. Cunning can be seen as another face of fluidity, encouraged by regulatory attempts that have little purchase and relation to the actual nature of the crime and culprits. This combined with the reluctance of free market neoliberal ideology to impose rules can drive the speed of flow to unprecedented turbulence, also of course driven by the speed of technological changes forcing the rules to be on a continuous race to catch up.

The advantage of the Homeric metaphor is to speak to a duality of processes and their interaction. There were rocks, cave and a multi-headed monster in Homer, mechanized petrification and empty self-importance in Weber. In Weber's time there were no decentralising restructuring of functions or globalising processes, so it would have been hard to think of companies in terms of multi-headed monsters, but now we could be excused for making that association. In terms of organizational practices, some have argued that we are moving towards a post bureaucratic form of management (Hoggett, 2007), but, as Paul Hoggett (ibid) also argued, in the British public sector this is only a part of the picture: a move to decentralization has produced operationally decentralized units, while increasing centralised control over the monitoring of their operations (multi-headed Scylla in the cave). The kind of control exercised is key here: rather than ethically based quality control, the quantitative logic of key performance indicators, outputs and competition, in other words the logic, and values, of the market has taken over from the logic of public services and the values associated with them, i.e. to provide a service rather than generate profit. The situation created by these two tendencies in combination is what I think the metaphor I propose is able to characterise. Living with Scylla one can be devoured, if not literally 
through redundancy, certainly in terms of one's soul and values. As Layton and Redman (2014) remind us: 'neoliberalism... is ...a form of governing the soul (Rose, 1990)' from which there is little escape. The cave is not a cage, in that it has an opening, but the fall would be precipitous if one tried to escape and if one were to survive the fall, most likely one would end up swallowed by the whirlpool. The only escape offered in the Odyssey is through either instrumentality (see earlier section) or individual cunning. In his second lone crossing of the straits Odysseus chose to sail close to Charybdis. He avoided being swallowed by holding onto the fig tree growing above the deadly whirlpool, while his raft was swallowed up and then spat out, allowing him, by wisely judging his timing, to get back on it. It is maybe no coincidence that the tree is a fig tree. As most children growing up in Mediterranean countries learn, this is not a weight-bearing tree. The solution here is short term: it uses a pretty flimsy tree structure, available to Odysseus on the basis of being alone: a single, cunning, or to use the preferred neoliberal terms, 'enterprising', supposedly selfsufficient (see Glynos, 2014) individual.

\section{'Specialists without spirit'}

To return to Weber, in his time progress was made of iron and steel, cog based machinery and, as Gabriel (2012: 2) also reminds us, a near contemporary of Weber with an obsessive compulsion for control, Frederick Winslow Taylor (1856-1915) made a virtue of this by advocating using a deskilled workforce, managed from above by 'rules, laws and formulae' derived from tabulated traditional knowledge (Taylor 1911, cited in Gabriel 2012: 2). Thus we saw the birth of command and control management and hierarchically structured fragmented processes that make employee skill irrelevant at best, inconvenient or dangerous at worst. Workers as cogs are more compliant and predictable, their outcomes can be measured, and they are accountable as well as controlled. Rational calculation and 
instrumental rationality were the predominant ways by which capitalism proceeded. This mostly operated in such extremes in factory production processes, but those of us working in public services see a similar procedural erosion of professional competence in target driven neo-liberal regimes of accountability. We may be living in a post-Fordist time, yet it seems that some principles, such as the breakup of functions and deskilled compliance, have mutated and migrated (another aspect of fluidity), rather than being superseded. Policies are now often co-terminus with procedures and protocols, in other words workers are no longer given a principle to guide their actions, rather they are told what to do and made fearful of using their own judgement, lest they fall foul of some regulation or another. More and more the letter of the law or rule, rather than its spirit is what is made to count, counting being the only way to judge performance in neo-liberal management. A recent UK example illustrates this: the House of Lords Economics Affairs Committee has recently reported that HMRC, the UK government tax collector, is failing to 'discriminate effectively' between the different kinds of activities it classes as tax avoidance, pointing out that 'there is a clear difference between deliberate and contrived tax avoidance by sophisticated, high income individuals, and uninformed or naïve decisions by unrepresented taxpayers' (Morrison, 2018: 1). In this as in the earlier Windrush scandal examples, what is being pointed out could be seen as a failure to appreciate qualitative differences, differences in kind (Deleuze, 1991), by workers compelled to follow rules, while driven by quantitative KPI's. More important though is that in such a situation it is to the workers' detriment to exercise judgment and differentiate even if they were trained or allowed to use their judgement. This in turn leads to a further proliferation of rules and procedures to offset this, whereby additional administrative functions and specialists are needed. To link to earlier GDPR example at our university we now have administrators with specialist knowledge of GDPR and administrators outweigh academics in terms of numbers, to the point that even keeping up with where to find advice or 
who is supposed to do what has become a task in itself. The more staff turns over and regulatory regimes change or proliferate, the more all this is required. Whereas in the 'Windrush' case there was a deliberate creation of a hostile environment, most of the time there appears to be a denial that the conditions created by neoliberalism are the drivers of malpractice and difficult work and living conditions. Aside from eroding professional capacity and creating specialists without spirit, Weber thought this could lead to an emptying out of character or to use Sennett's (1998) term its 'corrosion'.

\section{'sensualists without heart'- Narcissism as the psychopathology of our time}

Weber's quote speaks extremely well to the nature of narcissism and to its social construction. He points to both an inflated self-aggrandising self-obsession and an inner emptiness - 'this nullity'. What Weber seemed to prophetically identify was later taken up more fully in the light of psychoanalysis by Lasch (1978) in The Culture of Narcissism. Narcissism in Lasch's view is brought about by social conditions of (liquid) modernity. In turn there is also in Lasch a critique of the rise in a therapeutic expert psychologising of the 'social conditions of the suffering' reducing problems to an individual level. The emptying out of patriarchal authority and fragmentation of families and communities are seen as part of the problem. Families, localised communities and non-expert traditionally communicated values are seen as possible ways of regenerating old ideas and ideals. This led him to being criticised as conservative and nostalgic. The point that got missed according to De Vos (2010) is that Lasch was telling us about the deep inter-relation of the social and the psychological. Barry Richards (2018: 19) also re-evaluates Lasch's work as offering a ‘very deeply psychosocial model' that offers a 'perhaps unique attempt to capture the full psychosocial arc of change, from the unconscious of the adult parent through the primitive terrors and defences of the infantile psyche to the unconscious of the next adult generation' linked to changing practices and values in social and cultural milieus. In terms of my Homeric metaphor Lasch was telling us about the dangers of the extreme fluidity of late modernity and in terms of Weber's quote proposing a renewal of culture and values, one of the possibilities Weber mused about. 
In conditions of modernity adaptation (another aspect of fluidity) and appearance become values for a fragile identity, plagued not by guilt, but by anxiety, shame and depression. The link between anxiety and poor internal foundations for security giving rise to narcissism is present in Lasch (1978), but the lack of boundaries, and the concern with surface and appearance are the main elements that link to my current analysis. Students' mental health problems are increasing (see among others IPPR report: Thorley, 2017; Storrie et al. 2010). I experience first-hand this worrying increase in mental health issues among university students in my own work with undergraduates, many struggling with at least some of the features of narcissism. So many are plagued by anxiety about how others might judge them. There are selfie obsessions and increasing addiction to online social networking, where one's standing is numerically determined by the number of Facebook friends and 'likes' received, another aspect of the confusion between qualitative and quantitative aspects, whereby numbers take the place of qualitative aspects of relatedness. The fragility of identity, its instability and need for external validation, its continuous need for a curated presentation of self could be also seen as another face of fluidity, fuelling in turn the attachment to the many forms of identification available to the postmodern self as an expression for the need for some anchorage. Gender and sexuality are topics my first year students are most interested in. These issues are well covered in academic work and debate, but what is interesting in relation to my argument is the quality and relation of structure and fluidity in these identity issues. What I have noticed is that gender fluidity goes hand-in-hand with 'I identify as...' statements, an interesting substitution for the more conventional 'I am'. This is more about categorisation, than being; it is a flimsy structure to cling to, in the context of a wished for dissolution of standard binaries of gender and sexuality categories. As the standard categories that characterised organised modernity have been increasingly questioned, in the hope that differences could be embraced along a spectrum without discrimination, the need for some structure has resurfaced along with fraught debates as to who is included and excluded by the various initials associated with such: LGBT, LGBTQ, LGBTQI etc. This is in my view another aspect of the tension between fluidity and structure in terms of identity and its relation to individual and social aspects. The tendency to depression is another aspect of the fragility of identity and linked to narcissism (Bleichmar, 1991; 
Rosenfeld, 1971; Morrison, 1989; Anastasopoulos, 2007). Narcissism can be seen following Britton's (2004) summary and simplification of the extensive literature on the subject to be either libidinal/defensive or hostile/destructive. Mostly what I see in students appears to be of a libidinal in nature, briefly sketched here, before turning later to more destructive aspects.

Mark Fisher (2009: 22) talking of his experience of UK Further and Higher Education students spoke of 'hedonic' depression. This he characterised as 'constituted not by an inability to get pleasure, but by an inability to do anything else except pursue pleasure. There is a sense that 'something is missing'- but no appreciation that this mysterious, missing enjoyment can only be accessed beyond the pleasure principle (ibid, his italics).' In our university some of the cure being peddled for students' mental illness is a culture of positivity (the initiative overall has adopted the neologism of 'mental wealth'!) spread through a campaign of post-it notes ('you can do it'...) scattered across campus, as if there were no reasons to be depressed. Is this not an organisational level invitation to denial and further narcissistic omnipotence, rather than feeling the pain and acting to seek and denounce its actual source? As members of the institution UK academics are swimming in the same soup. While individually attempting to do our best by the students, survival fears often make us accomplices in the system, whether willing or not.

While the fragility of identity and the rise in narcissism in greater portions of populations is troubling, it is not usually as directly and immediately socially destructive as some of the more extreme manifestations to which I turn next. An extreme example of this are the disturbing and unprecedented recent atrocities perpetrated by young men who self-identified as 'Involuntarily Celibates' or INCELs. Their strong self-identification as victims and their envy of socially more competent peers in relationships drove them to commit atrocities: for example Elliott Rodger killed 7 and injured 14 college students in California University College Santa Barbara in 2014, and in 2018 Alek Minassian killed 14 women and injured 14 more, 10 of them women. Rodger was a heavy Internet user who, prior to the killings, posted YouTube videos and a manifesto where he portrayed his actions as beautiful just retribution (Blommaert, 2017). The killing was given an aesthetic value. Appearance here trumped ethical aspects of judgement. There are few boundaries to acceptable behaviours and an 
important aspect of narcissism is the refusal of boundaries and limitations, creating a real difficulty in terms of the ability of rules and regulations to contain destructive tendencies.

While there is evidence of destructive narcissism in such events, allied to misogynist and racist attitudes, my focus is not on individual pathology, but on the social conditions that exacerbated these traits. As Blommaert (2017) points out his relationships online and offline over time offered a structure for validation of his most violent fantasies, accelerated and validated his descent into an extreme projective dynamic, a doer/done to mentality, where it became legitimised to go from victim to aggressor. The lack of boundaries of the online environment offered a structuring whereby there could be a movement of positioning to the only place of agency available within a paranoid doer/done to view of the world. While not wishing to digress too much, I will close on this example by pointing out that this phenomenon has burst the boundaries of the dark recesses of the internet and the more extreme, mercifully still few murderous events perpetrated by INCELs: recently Nathan Larson, a self-identified INCEL paedophile ran for Congress in Virginia (Squirrel, 2018).

It appears our time is witnessing not just the engendering, but also the exacerbation and normalisation of pathology. Yet as Richards (2018: 21) points out, this last statement is itself controversial. Using both the work of Hofstadter (1964) and the example of the deliberations of the psychiatric panel commissioned to assess Anders Breivik's state of mind following the murder of 77 people in Norway in 2011, Richards points to the difficulty of pathologising 'normality': the commission declined to see Anders as insane, given that he could be seen as belonging to a subculture sharing his ideological and political perceptions (Thorissen and Aspass, 2012: Sec.21.5.2 cited in Richards, 2018: 21). Mad or bad? The boundaries are hard to draw, if we cannot accept that madness can affect social and political dynamics. As Richards (ibid) puts it: ' ...understanding the cultural supports of destructive movements or toxic leadership must involve accepting the pathological dimensions of everyday normality.' Richards (ibid: 24) avoids the issue however on whether it is right or possible to see society as such as pathological, preferring to limit his analysis to the case of Donald Trump. The more important point I want to take up from Richards (2018) however is that narcissism is not necessarily a destructive force in its own right. According to Hofstadter, Richards states, and more generally the concepts of malignant or negative narcissism in psychoanalytic literature (Kernberg, 1970; Rosenfeld, 1971, cited 
in Richards 2018) narcissism has to be allied to paranoia to be destructive, along with a perverse idealisation of destructive parts of the self. In Rodger's case there is an extreme sense of victimhood and persecution in conjunction with clear processes of splitting and projection towards 'others', perceived as hostile. Though I cannot be sure without having known the individual involved, it seems that an element of perverse idealisation of destructive parts of self could be gleaned in what I pointed out earlier as Rodger's description of his murderous actions as 'beautiful just retribution'. This section has looked at the kinds of people neoliberal capitalism is producing, from the increasingly common anxiety of students and links to narcissism to more extreme and violent forms of what could be seen as malignant cases of narcissism acting out atrocities. So far my argument overall is that the structures the neoliberal environment offers have taken away any sense of containment and are having a range of difficult effects on individuals and organisations. Nothing new in this argument, Weber, Lasch and more recently Harvey (2005), Layton (2010) and in this journal many others (2014, issue 19, vol. 1 and 2) have made the case that the neoliberal ideology has eroded the social welfare safety nets that were available particularly in the UK. This has given an atomised society, based on individuals, continuously assessed and self-assessing, increasingly anxious and insecure. Those who can suffer the pain, helplessness and rage are in a better place than those who disavow it in favour of grandiose omnipotent fantasies. What I am adding to the literature is that neoliberalism's corrosive impact often results from the interplay of fluidity and structure, their increased polarisation and reactive dysfunctional relatedness between them. As a consequence quality itself has become a confused notion, perverted in its nature by its equation with quantity and an obsession with surface and appearance. Available structures are flimsy, inconstant and quantitatively understood, yet at the same time rigidly applied and proliferating in some sectors: paradox and complexity abound. All kinds of distinctions have become blurred, students are consumers, yet paradoxically also outputs of my activity in terms of KPIs, as measured by numbers related to retention, progression and employment market ready graduates.

\section{From narcissism to perversion}


The previous section focused on individuals and touched on the element of perversion. Susan Long (2008) has pointed to this in relation to organisational life. In her book The Perverse Organisation and its Deadly Sins she points to 'evidence of a movement from a culture of narcissism towards elements of a perverse culture' (2008:1). Paul Hoggett (2010: 58) in agreement with Long summarises 'shifts in the psychic economy of capitalism, from instinctual repression (Freud 1929), to repressive desublimation (Marcuse 1966) and narcissism (Lasch 1978), and to a culture of perversion'. Long's analysis of perversion centres on case studies of Enron and Long-Term Capital Management as symptoms of wider social dynamics and Hoggett applies her work to political, social and governmental aspects. Five dimensions of perversion are given (also cited in Hoggett 2010: 57). In Long's (2008: 15) view perversion "has to do with individual pleasure at the expense of a more general good...(it) acknowledges reality, but at the same time, denies it...(it) engages others as accomplices to perversion...(it) may flourish where instrumental relations have dominance in society...perversion begets perversion." In relation to Long's first point about individual pleasure, Hoggett (2010: 58) points out that 'narcissism and perversion are adjacent and overlapping states of mind', citing the work of Davar (2004), Waddell and Williams (1991), Rosenfeld (1985) and continues by making 'the spread of collusion and organised self-deception... the hallmark of a distinctively perverse as opposed to a straightforwardly narcissistic culture' (ibid), this being the central feature of neo-liberal forms of capitalism and governance. What Hoggett identified as the structural support for the perverse social defence identified by Long is the blurring of real and false, a confusion between image and reality, fostered by both computer technology and the culture of performance indicators, where the indicators skew behaviour and managers act 'as if' they were reality in themselves. Ten years have passed since Long's book, eight since Hoggett's article. The idea of fake news and a president communicating via tweets was not around then, though it was a direction his article was presaging. Cunning and deception have become part of the everyday right through to the highest corridors of power. Their genesis is in the lack of containment that the reactive relation between structure and fluidity produces, in the resulting blurring of differences in kind and the emptying out of quality and meaning. The recent political events in Britain are characterised by this. Does 'Brexit means Brexit', Mrs May's 
original slogan as she took charge from David Cameron, not speak of meaninglessness in its obvious, yet never admitted tautology? Brexit was peddled on the basis of lies, and going back on one's words is part of how the most important decision of recent times for the UK is being managed. The behaviour of UK politicians is becoming characterised by extreme brinkmanship on all sides. Uncertainty and anxiety are rife as a result. In an increasingly uncontained and uncontainable environment growing turbulence and polarisation are the main features, with a deleterious effect on the economic growth it is meant to foster. It is hard to find anchorage or orientation, which could offer a modicum of containment. There is more to be explored here in relation to whether individual pleasure at the expense of the common good, as Long suggests, gives an accurate or sufficient answer to the issue of perversion. It seems to be more complex, with survival anxiety, whether exaggerated or realistically assessed, being at least a component of what may be going on. This is a rich seam for further research that requires more space for a fuller elaboration.

\section{Conclusion}

To conclude: the article has attempted to outline how an ancient tale can offer a new metaphor for our time of extremes. It has charted this in relation to some of the sociological metaphors and imaginations that have exerted enduring influence and been taken up by many for further elaboration and/or updating, before tracking how the relationship of structure and fluidity might be characterised as one of reactive and dysfunctional relating. Structures and systems are necessary aspects of life as is the capacity to be flexible. It is their extreme and perverted manifestations that become monstrous. The metaphor of Scylla and Charybdis contains important indications: it is the tension between fluidity and structural geographical features, i.e. constriction of water caused by land features positioning that creates the deadly whirlpool of Charybdis; land is no safer in these conditions as there lies the danger of cave and multi-headed Scylla. It is not land or water, structure and fluidity per se that constitute danger or salvation: it is their polarised dichotomy, their form, position and relationship. That is in itself a cultural and political matter that should lead us to question what containment might mean in terms of culture and politics. Squeezing and controlling, mistrust and dumbing down certainly are not that. 
What I have tried to characterise is the increasingly problematic relation and polarisation of processes in tension with each other. On the one hand there is a separation between areas where bureaucratic control is seen as paramount in saving us from chaos and corrupt practices, for example in the conceptualisation of the state's function as a brake (Mazzucato, 2018), rather than bureaucracy as an enabling function to accomplish tasks, while on the other there has been an equally misguided faith in fluidity per se, for instance the power of the economy to regulate itself. How we make a living does indeed affect how we feel and think, what culture we produce. The trouble is that the culture being produced is now often empty and out of balance, both in terms of inequalities and social justice and in relation to individual wellbeing.

Having compliant, non-questioning citizens is not only cheaper, but easier to manage in the short term at least. What is lost is a workforce and organisations that can think through problems, hold responsibility in the face of continuous change, manage themselves in complex situations and above all remember that our labour should be to the benefit of humankind, which of course include our environment, the planet that makes our lives possible. Being mindful of this higher ethical principle could create a thirdness that might allow us to lift our heads from the turmoil of competitive individualistic anxieties. It might give us the possibility of acknowledging both the reality of human suffering as well as the human potential for ingenuity, which I use here in contrast to cunning. What is gained by continuing in the neoliberal trajectory instead is an increase in real human suffering, including the destruction of our planet, while believing we have 'attained a level of humanity never before achieved'.

\section{References}

Anastasopoulos, D. (2007) The narcissism of depression or the depression of narcissism and adolescence. Journal of Child Psychotherapy Vol. 33 No. 3: 345 - 362

Bauman, Z. (2000) Liquid Modernity. Cambridge: Polity

Benjamin, J. (2004). Beyond doer and done to: an intersubjective view of thirdness. Psychoanalytic Quarterly, LXXIII: 5-46.

Bleichmer, H. (1996) Some subtypes of depression and their implications for psychoanalytic treatment. Int. J. Psycho-Anal. 77, 935 
Blommaert, J. (2017) Tilburg Papers in Culture Studies. 200. Online-offline modes of identity and community: Elliot Rodger's twisted world of masculine victimhood (online) https://www.researchgate.net/publication/321532864_Paper_Online-

offline_modes_of_identity_and_community_Elliot_Rodger's_twisted_world_of_masculine_v ictimhood [accessed 26-06-2018]

Britton, R. (2004) Narcissistic Disorders in Clinical Practice. Journal of Analytical Psychology Vol 49: 477-490

Bryant, A. (2007) Liquid Modernity, Complexity and Turbulence. Theory, Culture and Society Vol. 24(1):127-135

Clegg, S. and Baumeler, C. (2010) From Iron Cages to Liquid Modernity in Organization Analysis. Organization Studies 31(12): 1-21 ISSN 0170-8406

Courpasson, D. (2000) Managerial strategies of domination: Power in soft bureaucracies. Organization Studies 21/1: 141-161

Crociani-Windland, L. (2011) Festivals, Affect and Identity. London: Anthem Press

Davar, E. (2004) The perils of conviction: addiction, terror and leadership. Psychodynamic Practice, 10, 4: 439-458.

Deleuze, G. (1991) Bergsonism. New York: Zone Books.

De Vos, J. (2010) Christopher Lasch's The Culture of Narcissism-The Failure of a Critique of Psychological Politics. Theory and Psychology 20/4: 528-548.

Fisher, M. (2009) Capitalist Realism-Is there no alternative? London: Zero Books.

Foucault, M. (1977) Discipline and Punish. Harmondsworth: Penguin.

Freud, S. (1929) Civilization and its Discontents. SE, 21, 57-145.

Gabriel, Y. (2005) Glass Cages and Glass Palaces: Images of Organisations in Image Conscious Times. Organization vol. 12(1): 9-27.

Gabriel, Y. (2008) Spectacles of resistance and resistance of spectacles. Management Communication Quarterly 21/3: 310-326.

Gabriel, Y. (2012) Under New Management: Subjects, Objects and Hubris, New and Old. Nouvelle Revue de Psychosociologie Vol.13:241-264.

Glynos J. (2014) Neoliberalism, markets, fantasy: The case of health and social care. Psychoanalysis, Culture and Society Vol. 19, 1, 5-12.

Greenfield, A. (2006) The Dawning Age of Ubiquitous Computing. Berkeley, CA: New Riders.

Harvey, D. (2005) A Brief History of Neoliberalism. Oxford: Oxford University Press. 
Hobsbawm, E. (1994) The Age of Extremes: The Short Twentieth Century, 1914-1991. London: Michael Joseph.

Hofstadter, R. (1964) The paranoid style in American politics. Harper's Magazine, November.

Hoggett, P. (2007) New Modes of Control in the Public Service. Public Administration 74(1):9- 32.

Hoggett, P. (2010) Perverse Social Structures. Journal of Psycho-Social Studies Volume 4, Issue 1 , June 2010.

Homer (1999 ed.) The Odyssey. Trans S. Butler (online) Project Gutenberg: gutenberg.org.

Horkheimer, M. and Adorno, T. W. (2002 [1947]) Dialectic of Enlightenment: Philosophical Fragments, G. S. Noerr ed., Jephcott E. trans., Stanford, Calif.: Stanford University Press.

Institute for Public Policy Research Thorley (2017) NOT BY DEGREES IMPROVING STUDENT MENTAL HEALTH IN THE UK'S UNIVERSITIES available from https://www.ippr.org/publications/not-by-degrees [accessed 1-3-2019]

Lasch, C. (1978) The Culture of Narcissism. New York: Norton.

Lash, S. and Urry, J. (1987) The End of Organized Capitalism. Cambridge: Polity.

Layton, L. (2010) Irrational exuberance: Neoliberal subjectivity and the perversion of truth. Subjectivity Vol. 3, 3, 303-322.

Long, S. (2008) The Perverse Organisation and its Deadly Sins. London: Karnac.

Luckmann, T. (1991) The new and the Old in Religion. In Bordieu, P. and Coleman, J.S. (eds) Social Theory for a Changing Society. Boulder, CO: Westview.

Manley, J. (2018) Social Dreaming, Associative Thinking and Intensities of Affect. London: Palgrave.

Marcuse, H. (1964) One Dimensional Man: Studies in the Ideology of Advanced Industrial Society. London: Routledge \& Kegan Paul.

Mazzucato, M. (2018) The Entrepreneurial State: Debunking public versus private sector myths. London: Penguin.

Morrison, A. (1989) Shame the Underside of Depression. London: Routledge.

Morrison, C. (2018) HMRC treating taxpayers unfairly, House of Lords report says. The Independent (online) 12-4-2018 available from:

https://www.independent.co.uk/news/business/news/hmrc-taxpayers-unfair-treatment-loancharge-house-lords-report-parliament-a8666061.html [accessed 4th December 2018].

Richards, B. (2018) Exploring Malignancies: Narcissism and paranoia today. Psychoanalysis, Culture and Society Vol.23, 1, 15-27.

Ritzer, G. (1996) The McDonaldization of Society. Thousands Oaks, CA: Pine Forge. Press/Sage. 
Rosenfeld, H. (1987) Impasse and Interpretation. London: Routledge.

Sennett, R. (1998) The Corrosion of Character. London: Penguin/Allen.

Squirrel, T. (2018) Nathan Larson, the self-described incel paedophile, is running for congress. The Independent (online) 5 June available from:

https://www.independent.co.uk/voices/nathan-larson-incel-paedophile-dark-web-congressvirginia-a8384391.html [accessed 25-6-2018].

Storrie, K., Ahern, K., \& Tuckett, A. (2010). A systematic review: Students with mental health problems - a growing problem. International Journal of Nursing Practice, 16, 1-6.

doi:10.1111/j.1440-172X.2009.01813.x

Virgil (1998 ed.) The Aeneid. Oxford World Classics Trans C Day Lewis. Oxford: Oxford University Press.

Waddell, M. \& Williams, G. (1991) Reflections on perverse states of mind. Free Associations Vol. 22: 203-213.

Weber, M. (1904-05/1992) The Protestant Ethic and the Spirit of Capitalism, T. Parsons (trans.), A. Giddens (intro), London: Routledge.

Weber, M. (1919/1946) "Science as a Vocation" in From Max Weber. 